\title{
Biological Conversion of Sugars to Hydrocarbons Technology Pathway
}

Ryan Davis, Mary Biddy, Eric Tan, and Ling Tao National Renewable Energy Laboratory

Susanne Jones Pacific Northwest National Laboratory

NREL is a national laboratory of the U.S. Department of Energy, Office of Energy Efficiency \& Renewable Energy, operated by the Alliance for Sustainable Energy, LLC, under contract DE-AC36-08G028308.

Pacific Northwest National Laboratory is operated by Battelle for the United States Department of Energy under contract DE-AC05-76RL01830.

Technical Report

NREL/TP-5100-58054

PNNL-22318

March 2013

Prepared for the U.S. Department of Energy Bioenergy Technologies Office 


\section{Biological Conversion of Sugars to Hydrocarbons Technology Pathway}

Ryan Davis, Mary Biddy, Eric Tan, and Ling Tao National Renewable Energy Laboratory

Susanne Jones Pacific Northwest National Laboratory

NREL is a national laboratory of the U.S. Department of Energy, Office of Energy Efficiency \& Renewable Energy, operated by the Alliance for Sustainable Energy, LLC, under contract DE-AC36-08G028308.

Pacific Northwest National Laboratory is operated by Battelle for the United States Department of Energy under contract DE-AC05-76RL01830.

Technical Report

NREL/TP-5100-58054

PNNL-22318

March 2013

Prepared for the U.S. Department of Energy Bioenergy Technologies Office

National Renewable Energy Laboratory 15013 Denver West Parkway Golden, Colorado 80401 303-275-3000 • www.nrel.gov
Pacific Northwest National Laboratory P.O. Box 999

Richland, WA 99352

1-888-375-7665 • www.pnl.gov 


\section{NOTICE}

This report was prepared as an account of work sponsored by an agency of the United States government. Neither the United States government nor any agency thereof, nor the Alliance for Sustainable Energy, LLC, nor Battelle Memorial Institute, nor any of their employees, makes any warranty, express or implied, or assumes any legal liability or responsibility for the accuracy, completeness, or usefulness of any information, apparatus, product, or process disclosed, or represents that its use would not infringe privately owned rights. Reference herein to any specific commercial product, process, or service by trade name, trademark, manufacturer, or otherwise does not necessarily constitute or imply its endorsement, recommendation, or favoring by the United States government or any agency thereof. The views and opinions of authors expressed herein do not necessarily state or reflect those of the United States government or any agency thereof, or the Alliance for Sustainable Energy, LLC, or Battelle Memorial Institute.

Available electronically at http://www.osti.gov/bridge

Available for a processing fee to U.S. Department of Energy and its contractors, in paper, from:

U.S. Department of Energy

Office of Scientific and Technical Information

P.O. Box 62

Oak Ridge, TN 37831-0062

phone: 865.576 .8401

fax: 865.576.5728

email: mailto:reports@adonis.osti.gov

Available for sale to the public, in paper, from:

U.S. Department of Commerce

National Technical Information Service

5285 Port Royal Road

Springfield, VA 22161

phone: 800.553 .6847

fax: 703.605.6900

email: orders@ntis.fedworld.gov

online ordering: http://www.ntis.gov/help/ordermethods.aspx

Printed on paper containing at least $50 \%$ wastepaper, including $10 \%$ post consumer waste. 


\section{Biological Conversion of Sugars to Hydrocarbons}

\section{Developing Pathway Cases to Understand the Cost of Converting Biomass to Hydrocarbon Fuels}

In support of the Bioenergy Technologies Office, the National Renewable Energy Laboratory (NREL) and the Pacific Northwest National Laboratory (PNNL) are undertaking studies of biomass conversion technologies to identify barriers and target research toward reducing conversion costs.

Process designs and preliminary economic estimates for each of these pathway cases were developed using rigorous modeling tools (Aspen Plus and Chemcad). These analyses incorporated the best information available at the time of development, including data from recent pilot- and bench-scale demonstrations, collaborative industrial and academic partners, and published literature and patents. The economic results of these analyses are in the process of further refinement and will be published in FY13 and FY14 design reports. This report summarizes the preliminary technical data used for the models and identified data gaps.

This technology pathway case investigates the biological conversion of biomass-derived sugars to hydrocarbon biofuels, utilizing data from recent literature references and information consistent with recent pilot-scale demonstrations at NREL. Technical barriers and key research needs have been identified that should be pursued for the pathway to become competitive with petroleum-derived gasoline-, diesel-, and jet-range hydrocarbon blendstocks.

\section{Process Block Diagram}

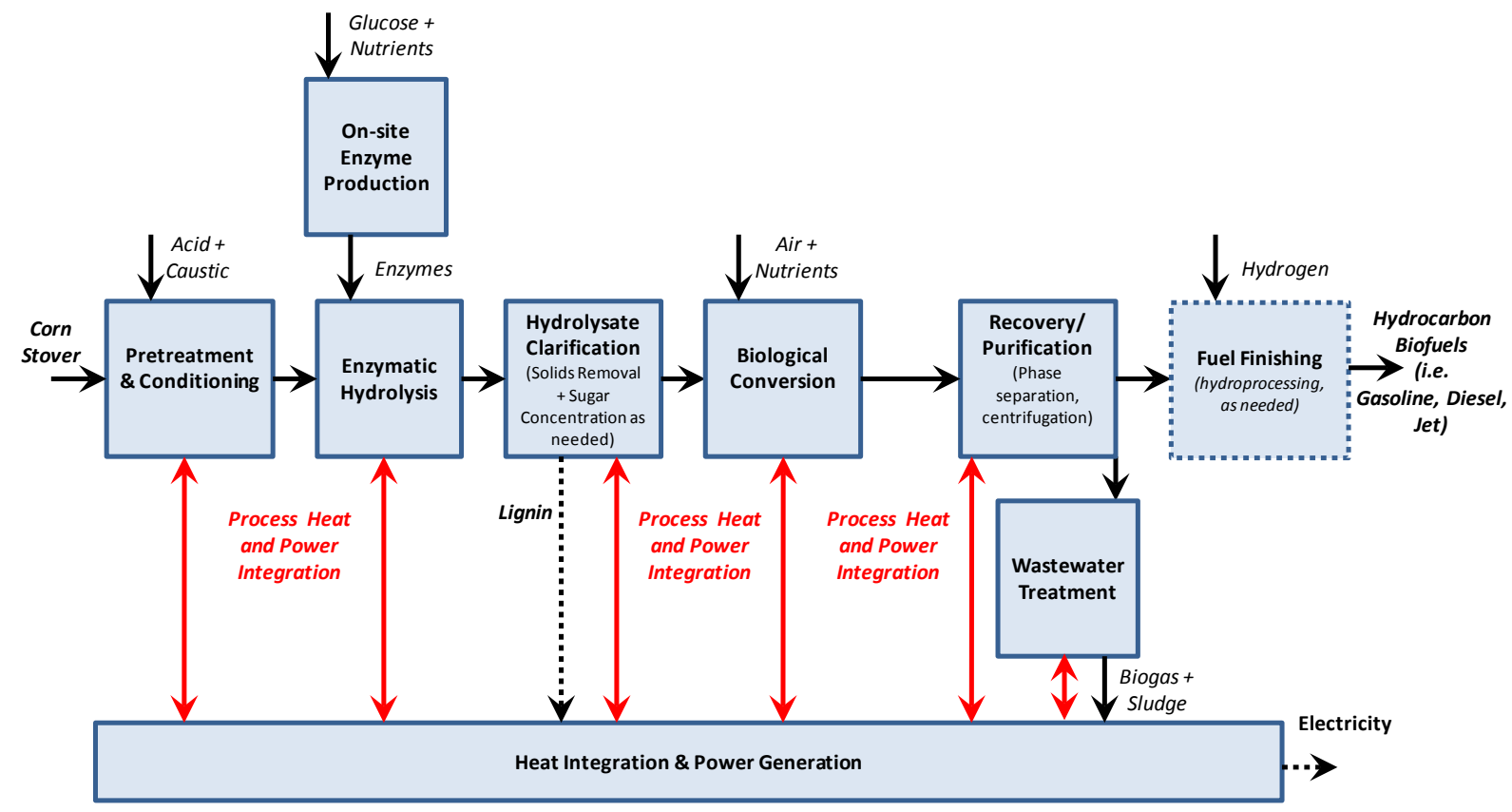




\section{Key Highlights}

- The biological conversion of sugars to hydrocarbons technology pathway has the potential to produce high-value, targeted fuel components with desirable properties. This pathway leverages prior experience in biochemical conversion technologies, specifically the production of sugars from cellulosic biomass.

- Microorganisms can be genetically engineered to produce targeted fuel components or co-products with high yields and value.

- The biological production pathway will produce a hydrocarbon intermediate that will generally require mild upgrading at a marginal cost to achieve a final fuel blendstock.

- Opportunities exist to reduce the conversion costs by focusing on process integration improvements. The sugar production steps (pretreatment and enzymatic hydrolysis) can be tailored to achieve a hydrolysate quality for maximized microbial conversion and improved process yields.

- Increasing overall biomass utilization toward value-added co-products will improve economic viability. New pathways for converting underutilized fractions of the biomass, including lignin and acetate, will need to be developed and demonstrated to increase overall product yields.

- Important research needs for this pathway include maximizing sugar (and/or carbon) utilization and microbe metabolic performance, improving tolerance of the microbes to lignocellulosic-derived sugar stream impurities, and developing routes for lignin utilization and alternative co-product opportunities.

\section{Process Design Details}

The biological conversion of sugars to hydrocarbons utilizes cellulosic sugars as the primary carbon and energy source for fuel production and microbial metabolism. This is analogous to ethanol fermentation in that sugars are biologically converted to fuel product(s); however, in the case of high yield hydrocarbon production it involves aerobic rather than anaerobic metabolism (the term "fermentation" strictly applies to anaerobic pathways such as that used for ethanol production, while most pathways considered here are based on "aerobic respiration" or "submerged aerobic cultivation"). As such, the production pathway largely follows similar steps as described in the NREL 2011 biochemical ethanol design report (Humbird et al. 2011) up through cellulosic sugar production, with a number of downstream modifications primarily around sugar conversion and product recovery, which carry important implications for an integrated process.

Feed handling: Corn stover, with a mean particle size of $<0.25$ inch, a carbohydrate content of $59 \mathrm{wt} \%$, and a moisture content of $<20 \mathrm{wt} \%$, is delivered to the feed handling area at a rate of 2,000 dry metric tons per day. All costs associated with feed handling operations are included in the delivered feedstock price. From there, the biomass is conveyed to the pretreatment reactor.

Pretreatment and conditioning: In this area, the biomass is treated with dilute sulfuric acid (nominally $5-25 \mathrm{mg}$ sulfuric acid $/ \mathrm{g}$ dry biomass) at a moderately high temperature $\left(150^{\circ}-200^{\circ} \mathrm{C}\right)$ for a short time (5-30 minutes) to liberate the hemicellulose sugars and make the biomass susceptible to enzymatic hydrolysis. The whole pretreated slurry is adjusted to $\mathrm{pH} \sim 5$ for 
enzymatic hydrolysis. Pretreatment is operated at $30 \mathrm{wt} \%$ total solids, consistent with the 2011 NREL biochemical ethanol design (Humbird et al. 2011).

During the recent 2012 state of technology pilot-scale demonstration at NREL, strategies focused on improving process integration were important to reducing conversion costs. One modification to the 2011 NREL biochemical ethanol design case explored the addition of a deacetylation preprocessing step, whereby feedstock is first soaked in dilute sodium hydroxide and then drained to remove a significant portion of acetate prior to dilute-acid pretreatment. Acetate, a derivative of acetic acid, is a known inhibitor for both enzymatic hydrolysis and ethanol fermentation. Adding this upfront preprocessing step not only improved sugar yields from enzymatic hydrolysis and ethanol yields from fermentation, it also reduced processing costs by removing a portion of the unconverted lignin fraction and lowering the pretreatment severity requirements (resulting in lower capital and operating costs) (Tao 2012).

The benefit of a deacetylation preprocessing step in the present hydrocarbon pathway is ambiguous because, unlike ethanologens, hydrocarbon production microorganisms may tolerate acetate (NABC 2012). A continued research emphasis on understanding the process integration of the biofuels refinery will be critical to improving the overall economics and maximizing hydrocarbon yields. Optimizing upstream processes, including preprocessing and pretreatment strategies, will be important to produce a hydrolysate stream with the qualities and composition best suited for fuel production. Further expanding opportunities for producing value-added coproducts from currently underutilized fractions of the biomass, including the lignin and acetate fractions, will also be a key driver toward improving the economic viability of this conversion pathway.

Enzymatic hydrolysis: Enzymatic hydrolysis is initiated in a high-solids continuous reactor (24hour residence time) using a cellulase enzyme prepared on-site (described below). The partially hydrolyzed slurry is next batched to one of several parallel reactors. Hydrolysis is completed in the batch reactors, which are modeled in NREL's 2011 design case as 1-million-gallon tanks operating at a 60-hour batch time (2.5 days) (Humbird et al. 2011). While these hydrolysis conditions may remain fixed, enzyme loading is a primary variable and cost driver in the biochemical process design. In the recent 2012 state of technology pilot-scale demonstration runs at NREL, overall glucan-to-glucose conversions of 78\%-82\% were observed using an enzyme loading of $19 \mathrm{mg}$ enzyme protein/g cellulose (mg/g hereafter) and $89 \%$ at $26 \mathrm{mg} / \mathrm{g}$ (Chen et al. 2012; Tao et al. 2013; Tao et al. 2012); thus, the state of technology as demonstrated by NREL at pilot scale suggests that favorable (high) glucose yield and (low) enzyme loading can both be currently achieved, albeit at a slight trade-off between the two metrics compared to targets described in Humbird et al. (2011).

Going forward, further room for improvement exists to maintain high glucose yields while continuing to reduce enzyme dosage as ever better enzyme cocktails are developed. This represents an important research area for the biological conversion pathway to achieve economic viability that is highlighted in the U.S. Department of Energy's (DOE's) recently-released "Conversion Technologies for Advanced Biofuels (CTAB) Roadmap" (DOE 2012).

Hydrolysate clarification: After enzymatic hydrolysis is completed, the saccharified slurry or hydrolysate is clarified using a filter press to remove remaining insoluble solids, primarily lignin- 
rich residues. This represents a deviation from the biochemical cellulosic ethanol model in which lignin-rich solids are not removed until after sugar fermentation. However, unlike anaerobic processes like ethanol fermentation, most hydrocarbon biofuels conversion pathways are aerobic and the presence of solids will adversely interfere with necessary gas-liquid oxygen mass transfer and limit oxygen uptake rates, and it may also impede complete hydrocarbon product recovery. Additionally, the majority of literature studies for microbial production of hydrocarbon biofuels, besides ethanol and butanol, focus on using relatively clean, insoluble-solids-free sources of sugars (e.g., sugarcane juice, corn syrup).

It remains unclear whether removal of residual lignocellulosic (and other) insoluble solids is a prerequisite for microbial hydrocarbon production pathways, but solids removal before the conversion step is assumed here for a base case process design. The use of a filter press with solids washing prior to biological conversion results in a small sugar loss, as low levels of sugars remain in the lignin-rich solids stream. If possible, performing the solids removal separation process downstream of sugar conversion would be preferable to maximize yield. The lignin-rich residues removed from the process represent an additional potential source of fuels and coproducts through development of new conversion methods.

Subsequent to solids removal, the sugar stream may be sent directly to the biological conversion step or may be further processed to concentrate the sugars by evaporation or other means (e.g., reverse osmosis or nanofiltration). While utilizing dilute $(100-150 \mathrm{~g} / \mathrm{L})$ sugars is the approach taken in biochemical cellulosic ethanol production (Humbird et al. 2011), concentrated commodity sugars ( $\geq 500 \mathrm{~g} / \mathrm{L})$ are utilized in many literature reports on hydrocarbon biofuels production (e.g., Renninger 2008). Different processing schemes for the biological conversion step also require different optimum sugar concentrations, with higher sugar concentrations being more conducive to fed-batch operation versus batch operation. Although overall bioreactor volumes can be similar in either case if volumetric productivities (i.e., $\mathrm{g} / \mathrm{L} / \mathrm{h}$ ) are similar, there are additional impacts to downstream unit operations within the context of an integrated process model if concentrated sugars are used.

To reach economic targets going forward, it will be important to better understand and quantify the trade-offs between biological conversion of relatively dilute sugars versus the conversion of more concentrated sugars that require additional costs for sugar concentration but potentially result in higher product titers and/or more efficient water management and bioreactor utilization.

Biological conversion: Consistent with most biological pathways for hydrocarbon production, the conversion step is likely to proceed via aerobic respiration rather than anaerobic fermentation. Because biochemical ethanol production proceeds via anaerobic fermentation, hydrocarbon conversion operations are modified considerably from the biochemical cellulosic ethanol design, which utilizes 1-million-gallon fermentor tanks (Humbird et al. 2011). These modifications include the addition of air compressors as well as the use of smaller bioreactor vessels with more powerful agitation systems to enable the higher agitation rates required to achieve oxygen gas-liquid mass transfer (relative to anaerobic fermentation where only bulk mixing of the slurry is required). Because oxygen is only sparingly soluble in aqueous broths, the need to maintain aerobic conditions via continuous aeration is foremost among technical challenges to economically scale up this operation. It is anticipated that the ability to maintain effective gas-liquid mass transfer (i.e., sufficiently high volumetric oxygen transfer rates) will 
ultimately limit the size at which microbial fuel production can be operated to considerably smaller volumes than are possible for anaerobic processes. For example, the largest bioreactor scale yet reported publicly for biological upgrading of sugars to hydrocarbons is approximately 50,000 gallons (200,000 L) (Pray 2012), although it is expected that with further process optimization it may be possible to increase maximum vessel size beyond this value. Moreover, aeration is generally costly to implement, as air compressors and relatively powerful motors are often needed to supply the large quantities of air and vigorous levels of agitation necessary to maintain adequate oxygen transfer rates. For instance, a preliminary assessment of an industrial process for producing ethanol, yeast, and lignin products found the cost of aeration for yeast cultivation to be roughly equivalent to the cost of enzymes for cellulose hydrolysis (Kollaras et al. 2012).

In light of these considerations, to achieve economic viability it will be important to evaluate the engineering design of microbial fuel production in detail to establish a realistic optimum system design at which aerobic conversion may proceed at acceptably large scale and low cost.

It is also worth noting that not all microbial pathways to hydrocarbons must necessarily proceed aerobically. For example, as proof of concept, NREL researchers have demonstrated using anaerobic fermentation in the lab to produce low quantities of hydrocarbon fuel using engineered Zymomonas mobilis (Zhang, M. 2012). Additionally, many anaerobic conversion pathways to produce intracellular and extracellular hydrocarbon products and intermediates exist in various bacteria and yeast microorganisms (Ladygina et al. 2006).

Thus, while the ability to produce hydrocarbons at high yields anaerobically remains to be proven, potential pathways are available to produce hydrocarbon biofuels by microbial conversion without the need to incorporate more complex and costly aeration capabilities into bioreactor systems. However, it is likely that the development and readiness of such pathways for near-term deployment will lag that of already developed and partially demonstrated aerobic biological pathways to hydrocarbon (or near hydrocarbon) products such as fatty acids, triglycerides, isoprenoids, and paraffins (DOE 2012; Huang and Zhang 2011; Liu and Khosla 2010; Rude and Schirmer 2009).

Aside from engineering and design challenges, from a process standpoint the primary cost drivers for the conversion stage are product yield and volumetric productivity $(\mathrm{g} / \mathrm{L} / \mathrm{h}$ of product being produced). Recent literature suggests that the current state of technology for microbial conversion to hydrocarbon biofuels includes product titers ranging from 0.1 to $24 \mathrm{~g} / \mathrm{L}$ of longchain hydrocarbons (Dellomonaco et al. 2011; Peralta-Yahya et al. 2011; Steen et al. 2010; Rude and Schirmer 2009; Renninger and Mcphee 2008), with times for batch or fed-batch production ranging from 2 to 7 days (Zhang, F. et al. 2011).

To achieve economic targets going forward, manipulation of the microorganism and optimization of the production process will be important research and development (R\&D) strategies. There remains considerable room for improvement in the efficiency of sugar conversion to fuel, particularly for utilization of pentose sugars, across a variety of hydrocarbonproducing microorganisms (Zhou et al. 2012; Hawkins 1999; NABC 2012). Further improving specific productivity rates (g product/g cell/h) by targeting a lower diversion of sugar to microbial cell growth and/or engineering ways to recover and reuse microbial cells (e.g., cell 
retention or cell recycle bioreactor configurations) as well as mitigating potential hydrocarbon product toxicity effects will increase overall process yields and improve economic viability.

The most ideal scenario for minimizing downstream processing requirements is for the fuel product or intermediate to be secreted from the cell into the aqueous broth and to phase-separate into a second product-rich liquid phase. However, some microorganisms (such as heterotrophic algae) may accumulate fuel precursor molecules intracellularly and will require dedicated extraction or alternative post-production cell wall lysis unit operations to be incorporated to recover the desired product. Product secretion will therefore remain an important preferential route toward achieving economic targets, which, combined with the need to obtain high product titers, also dictates the need for the microorganism to be resistant to toxicity effects of the secreted product(s). Although batch sugar fermentation is stipulated in the biochemical ethanol design model (Humbird et al. 2011), running the process in fed-batch mode could potentially reduce processing and economic challenges to achieving increased hydrocarbon yields and titers.

Product recovery/processing: For pathways where the product is secreted from the cell, the bioreactor product broth primarily contains the hydrocarbon product and water. Additionally, because most of the insoluble solids were removed prior to this step, only a small amount of insoluble solids such as microbial cell mass are present in the broth. A distinct advantage of diesel-range hydrocarbon products over short-chain alcohols, such as ethanol, is their typically low solubility in water, which can be exploited to allow for product separation and recovery via simple phase-separation methods rather than more costly and energy-intensive distillation. The lighter phase containing the long-chain hydrocarbon product may first be concentrated in a standard decanter vessel. The resulting hydrocarbon-rich phase may then be centrifuged to recover the desired product at high purity. Because the aqueous phase exiting product separation contains high levels of inorganic salts such as ammonium sulfate, excess nutrients, and soluble inorganic compounds, the aqueous stream is directed to wastewater treatment for cleanup (noted below) and chemical and energy recovery. The current product recovery scheme, which resembles those reported in the literature (e.g., Rude and Schirmer 2009), results in considerable savings in energy and capital costs as compared with energy-driven separation processes (e.g., azeotropic distillation) or mass separation (e.g., solvent extraction or absorbent-based) schemes.

As noted above, some microbial hydrocarbon production and recovery pathways may require additional extraction or cleanup steps to be incorporated, incurring additional costs. The exact recovery yields and product losses in these designs need further quantification and potentially further optimization. For example, product recovery yields may be reduced in a secreted product scenario due to emulsification with extracellular proteins or attachment or adsorption to cell or other residual solid surfaces. Additionally, while some products may already be a blendstock (for example, paraffins such as pentadecane [Rude and Schirmer 2009]), others such as fatty acids, fatty alcohols, or isoprenoids will require a final upgrading step such as mild hydrotreating to saturate the molecule(s) and remove oxygen to produce the final fuel or blendstock product.

Cellulase enzyme production: An on-site enzyme production section is included in this design, with all design and cost assumptions left unchanged from the biochemical cellulosic ethanol design case (Humbird et al. 2011). Purchased glucose (corn syrup) is the primary carbon source for enzyme production. Media preparation involves a step in which a portion of the glucose is converted to sophorose to induce cellulase production. The enzyme-producing fungus (modeled 
after Trichoderma reesei) is grown aerobically in fed-batch bioreactors. The entire enzyme production broth, containing the secreted enzyme, is fed to the enzymatic hydrolysis reactor. No stabilization or formulation of the enzyme production broth occurs. Beyond improving the enzyme production characteristics of the fungal host microorganism (e.g., higher specific activity enzymes, increased enzyme production yields), opportunities to further reduce enzyme production cost include evolving the production process to use lower-cost biomass-derived sugars rather than corn syrup as the primary carbon source.

Wastewater treatment: Wastewater streams are treated by anaerobic and aerobic digestion. The methane-rich biogas from anaerobic digestion is sent to the combustor, where sludge from the digesters is also burned. The treated water is suitable for recycling and is returned to the process.

Storage: This area provides bulk storage for chemicals used and produced in the process, including corn steep liquor, ammonia, sulfuric acid, nutrients, water, and fuel product.

Combustor, boiler, and turbogenerator: The insoluble lignin-rich residues from the solids separation step, the solids from wastewater treatment, and the biogas from anaerobic digestion are combusted to produce high-pressure steam for electricity production and process heat in the base case design. Any excess steam is converted to electricity for use in the plant and sold to the grid as a co-product. Opportunities exist to improve process economics by developing highervalue uses for one or more of these residual solids streams.

Utilities: This area includes a cooling water system, chilled water system, process water manifold, and power systems.

\section{Data Gaps, Uncertainties, and Research Needs}

The pathway for biological conversion of sugars allows the opportunity to leverage experience in biochemical processing, specifically cellulose and hemicellulose deconstruction to monomeric sugars as currently utilized in anaerobic fermentation to ethanol. Significant opportunities exist to further enhance front-end sugar production while concomitantly reducing uncertainty in downstream biological conversion and improving overall process integration. The goal of this pathway is to reach a minimum fuel selling price of \$3/gallon of gasoline equivalent (in 2011 U.S. dollars). To reach this targeted product price, the key bottlenecks, uncertainties, and areas for further development are summarized as follows:

- Investigate synergistic opportunities for sugar/intermediate production and process integration. The sugar production metrics tied to pretreatment and enzymatic hydrolysis will continue to be important areas for further R\&D improvement through the use of alternative or milder pretreatment options and/or improved enzyme performance (higher conversion yields and/or lower enzyme doses or cost), including incorporation of new enzyme classes and enzymatic hydrolysis mechanisms. Additionally, components that previously inhibited ethanol fermentation and could be removed early in pretreatment (such as acetic acid) may not pose such inhibitory effects in hydrocarbon biofuels pathways. Developing methods to utilize biomass-derived intermediates beyond monomeric sugars will also help to improve overall carbon conversion efficiencies in the process. Tailoring the hydrolysate stream to the microorganism tolerance will be essential for improving overall yields and lowering production costs. Another potential pathway to 
optimize process integration is "direct microbial conversion" (also known as consolidated bioprocessing), whereby enzymatic hydrolysis and fuel production occur in a single step without the need for added enzymes. Given the still relatively high cost of enzyme addition, this approach also warrants continued consideration and research.

- Develop separation and conditioning requirements for hydrolysate. A better understanding is needed of the tolerance of hydrocarbon-producing microbes to soluble lignin and other cellulosic sugar substrate impurities, including organic acids, salts, and other potential inhibitors. The efficacy of insoluble lignin removal following enzymatic hydrolysis may be more challenging and expensive than currently anticipated. Losses of sugar in this removal step will lower yields and increase costs and thus must be minimized. The performance and cost trade-offs between sugar stream concentration and purity and microbial hydrocarbon production must be quantified to be able to develop optimal process designs. These trade-offs are complex and will differ for different microbes, fuel products, and hydrocarbon production process configurations.

- Optimize design and scale for aerobic fuel production. The optimal engineering design and operating parameters for the aerobic microbial hydrocarbon production process must be identified. This includes determining the most economical bioreactor design that will allow the combination of maximum vessel size and process productivity and yield while minimizing the requirement and cost for vessel aeration and temperature control. Producing hydrocarbon biofuels by anaerobic microbial conversion and reducing the need to incorporate more complex and costly aeration capabilities into bioreactor systems should also be considered in parallel to improve process economy. The demonstration and development of microbes that can produce hydrocarbons at high rates and yields via anaerobic pathways would be a breakthrough for this field.

- Maximize sugar (and/or carbon) utilization and microbe metabolic performance. Better understanding is needed regarding the productivity of the fuel production microorganism and the potential of genetic engineering to significantly increase metabolic production rates and yields, minimize side-product formation, mitigate substrate and/or product toxicity effects, and otherwise develop highly robust conversion microbes. There is currently a dearth of literature and high quality data in the public domain on sugar uptake/conversion and microbial productivity, particularly with respect to production using cellulosic feedstock-derived substrates containing pentose sugars. Improving fuel production performance metrics will be instrumental in achieving cost targets; indeed, the CTAB Roadmap report notes "engineering of microorganisms for producing hydrocarbon-based biofuels in yields, titers, and rates high enough to be useful for commercialization requires significant effort in not only engineering of microbial metabolism for hydrocarbon biofuel synthesis at high yields, but also engineering the microorganisms' capability for utilization of the lignocellulosic substrates" (DOE 2012).

- Define product separation and final polishing/upgrading requirements. The recovery of products that are secreted directly into the aqueous broth presents challenges such as lowered yields due to products being retained on or within the cell mass, difficulties in breaking emulsions, and incomplete phase separation. Beyond these separation issues, additional finishing steps may be needed to improve product quality to meet fuel 
specifications. The product recovery and final upgrading operations need to be defined to quantify process costs and equipment requirements.

- Evaluate co-product opportunities. The requirement to reach a production cost (minimum selling price) target of $\$ 3 /$ gallon of gasoline equivalent will likely require simultaneous cost reductions in multiple areas (e.g., by way of engineering improvements and lower chemical/enzyme demands) and higher total product yields. To achieve the latter, carbon efficiency and total yields may need to improve beyond theoretical limits imposed by the metabolic conversion of sugar stream components alone (i.e., sugars derived from cellulose and hemicellulose). It will be important to develop cost-effective technologies to also convert non-sugar components (e.g., lignin, acetate) into value-added co-products, fuels, or fuel precursors. A life cycle assessment evaluating the trade-offs associated with diverting some process streams and residues to additional co-products will be critical for developing an economic and sustainable hydrocarbon fuels biorefinery facility.

\section{Summary and Next Steps}

This literature-based techno-economic analysis of biological conversion of corn stover to hydrocarbon biofuels was performed to identify technology gaps, uncertainties, and research needed to achieve a targeted minimum fuel selling price of $\$ 3 /$ gallon of gasoline equivalent. A design case detailing this pathway will be developed in FY13.

\section{References}

Blanch, H.W. (2012). "Bioprocessing for Biofuels.” Current Opinion in Biotechnology (23:3); pp. 390-395.

Chen, X.; Tao, L.; Shekiro, J.; Mohaghaghi, A.; Decker, S.; Wang, W.; Smith, H.; Park, S.; Himmel M.; Tucker M. (2012). "Improved Ethanol Yield and Reduced Minimum Ethanol Selling Price (MESP) by Modifying Low Severity Dilute Acid Pretreatment with Deacetylation and Mechanical Refining: 1) Experimental." Biotechnology for Biofuels (5); 60.

Dellomonaco, C.; Clomburg, J.M.; Miller, E.N.; Gonzalez, R. (2011). "Engineered Reversal of the Beta-Oxidation Cycle for the Synthesis of Fuels and Chemicals." Nature (476); 355.

DOE. (2012). “Conversion Technologies for Advanced Biofuels: Preliminary Roadmap \& Workshop Report." Whitepaper, December 2011 (issued for comment October 2012).

Washington, DC: U.S. Department of Energy. https://www.fedconnect.net/fedconnect/?doc=DEFOA-0000775\&agency=DOE.

Hawkins, R.L. "Utilization of Xylose for Growth by the Eukaryotic Alga, Chlorella." Current Microbiology (38); pp. 360-363.

Huang, W.D.; Zhang, Y.H.P. (2011). "Analysis of Biofuels Production from Sugar Based on Three Criteria: Thermodynamics, Bioenergetics, and Product Separation.” Energy \& Environmental Science (4:3); pp. 784-792. 
Humbird, D.; Davis, R.; Tao, L.; Kinchin, C.; Hsu, D.; Aden, A.; Schoen, P.; Lukas, J.; Olthof, B.; Worley, M.; Sexton, D.; Dudgeon, D. (2011). Process Design and Economics for

Biochemical Conversion of Lignocellulosic Biomass to Ethanol: Dilute-Acid Pretreatment and Enzymatic Hydrolysis of Corn Stover. NREL/TP-5100-47764. Golden, CO: National Renewable Energy Laboratory, May 2011. http://www.nrel.gov/biomass/pdfs/47764.pdf.

Kim, J.; Yu, K.; Leng, J.; Santolini, M.; Weisshar, J.; Castle, J.; Gray, D.; Sato, S.; Bass, T.S.; Ramirez, W.; Dorin, G.; Henry, R.; Pray, T.; Eppler, R.; Bellisimi, E.; Harris, S.; Rebolledo, J.P.; Chapeaux, A.; Poon, P. (2012). "Production of the Sustainable Renewable Biofuels Farnesane from US Domestic Sweet Sorghum." Oral presentation at the 34th Symposium on Biotechnology for Fuels and Chemicals, May 2012.

Kollaras, A.; Koutouridis, P.; Biddy, M.; McMillan, J.D. (2012). "Multiple Coproducts Needed to Establish Cellulosic Ethanol Industry." Ethanol Producer Magazine (online July 10, 2012).

Ladygina, N.; Dedyukhina, E.G.; Vainshtein, M.B. (2006). "A Review on Microbial Synthesis of Hydrocarbons.” Process Biochemistry (41:5); pp. 1001-1014.

Li, X.; Xu, H.; Wu, Q. (2007). "Large-Scale Biodiesel Production from Microalga Chlorella protothecoides through Heterotrophic Cultivation in Bioreactors." Biotechnology and Bioengineering (98); pp. 764-771.

Liu, T.G.; Khosla, C. (2010). "Genetic Engineering of Escherichia coli for Biofuel Production." Annual Review of Genetics (44); pp. 53-69.

National Advanced Biofuels Consortium (NABC). (2012). "Amyris Successfully Makes Biofene from Cellulosic Hydrolysate.” NABC news release, July 25, 2012.

http://www.nabcprojects.org/pdfs/amyris_makes_biofene_from_cellulosic_hydrolysate.pdf.

Peralta-Yahya, P.P. et al. (2011). "Identification and Microbial Production of a Terpene-Based Advanced Biofuel.” Nature Communications (2); 483.

Renninger, N.S.; Mcphee, D.J., U.S. patent 7,846,222 (2008). "Fuel Compositions Comprising Farnesane and Farnesane Derivatives and Method of Making and Using Same."

Rude, M.A.; Schirmer, A. (2009). "New Microbial Fuels: A Biotech Perspective." Current Opinion in Microbiology (12); pp. 274-281.

Schirmer, A.; Rude, M.A.; Li, X.; Popova, E.; del Cardayre, S.B. (2010). "Microbial Biosynthesis of Alkanes." Science (329); pp. 559-562.

Steen, E.J. et al. (2010). "Microbial Production of Fatty-Acid-Derived Fuels and Chemicals from Plant Biomass.” Nature (463); 559.

Tao, L. et al. (2013). "Techno-economic analysis of the dilute sulfuric acid and enzymatic hydrolysis process for the conversion of corn stover to ethanol." (in preparation). 
Tao, L.; Chen, X.; Kuhn, E.; Tucker, M.; Aden A.; Elander. R.T. (2012). "Improved Ethanol Yield and Reduced MESP by Modifying Low Severity Dilute Acid Pretreatment with Deacetylation and Mechanical Refining: 2) Techno-Economic Analysis." Biotechnology for Biofuels (5); 69.

Zhang, F.Z.; Rodriguez, S.; Keasling, J.D. (2011). "Metabolic Engineering of Microbial Pathways for Advanced Biofuels Production." Current Opinion in Biotechnology (22:6); pp. $775-783$.

Zhang, M. (2012). "Metabolic Engineering of Zymomonas mobilis for Hydrocarbon Fuels Production." Presented at the 2012 SIMB Annual Meeting.

Zhou, H.; Cheng, J.S.; Wang, B.L.; Fink, G.R.; Stephanopoulos, G. (2012). "Xylose Isomerase Overexpression along with Engineering of the Pentose Phosphate Pathway and Evolutionary Engineering Enable Rapid Xylose Utilization and Ethanol Production by Saccharomyces cerevisiae." Metabolic Engineering (14:6); pp. 611-622. 